\title{
Traducción feminista:
}

conciencia de género, intervencionismo y estrategias

Pilar Querol Pérez

al314200@uji.es 
I. Resumen

\section{Resumen}

Este trabajo parte de la base de que existe una relación entre lenguaje y género de la que la traductora ha de ser consciente cuando traduce un texto. Haciendo uso de esta conciencia se puede percibir que el lenguaje no se emplea de forma paritaria, sino que es esencialmente patriarcal y a través de este uso abusivo se han conformado las estructuras sociales y políticas vigentes hoy en día que se caracterizan por sus incontables argucias para invisibilizar y excluir a las mujeres.

Una de las formas mediante las que puede subsanarse esta concepción de superioridad lingüística masculina es la traducción feminista, el punto de convergencia entre feminismo y traducción y concepto en torno al que gira mi trabajo. Esta práctica traductora supone una manipulación deliberada del texto meta con el objetivo de que las mujeres por fin puedan sentirse representadas a través del lenguaje y se apoya en la idea de que deconstruir el sexismo lingüístico significa deconstruir el sexismo sociopolítico.

Sin embargo, esta práctica es intrépida debido a su falta de normalización y en la mayoría de ocasiones se tildará a la traductora de infiel y subversiva por las técnicas y estrategias de las que haga uso para alcanzar sus objetivos.

Este trabajo no es un análisis traductológico al uso; se trata más bien de una exploración de las cuestiones que me han resultado más sugestivas y destacables acerca de la traducción feminista a medida que he ido nutriendo y ampliando mis conocimientos sobre esta con ayuda, por supuesto, de la bibliografía en la que me he basado.

Palabras clave: traducción, feminista, género, feminismo, conciencia, patriarcal.

\section{Introducción}

La motivación principal de este trabajo reside en mi gran y creciente interés por los dos ámbitos de estudio en los que puede encuadrarse: los estudios de traducción e interpretación y el feminismo. A lo largo de estos años en el grado, me han surgido innumerables dudas sobre cómo poder llegar a hacer una buena traducción y preservar mi moral desde un enfoque feminista al mismo tiempo sin que pudiera parecer que cometía una y otra vez una simple y deliberada traición al texto origen. A pesar de que no eran textos problemáticos en cuanto a contenido, en la mayoría de ocasiones estas dudas estaban relacionadas con cuestiones de género que ahora, dado que tengo unos conocimientos más 
profundos y una ideología al respecto mejor fundada, etiquetaría como cuestiones relacionadas con el feminismo.

Tal y como Lori Saint-Martin $(1992,206)$ cita en su artículo "Susanne de Lotbinière-Harwood : Re-belle et infidèle : la traduction comme pratique de réécriture au féminin. The Body Bilingual : Translation as a Rewriting in the Feminine», existe una interesante analogía metafórica entre la traducción y la mujer: "Une traduction, c'est comme une femme; si elle est belle, elle risque d'être infidèle (...) infidèles à la loi du langage patriarcal.»

También otras traductoras y traductólogas feministas equiparan el estatus de la traducción, relegado a un segundo plano y considerado inferior, con la marginación actual de las mujeres, lo que desemboca en una doble discriminación (Bertacco 2003, 234; Calzada Pérez 2007, 104; Munday 2001, 131).

Por ello, podría hacerse una comparación, sin riesgo de que pareciera descabellada, entre el estatus de la figura de la traductora y de la mujer en sí misma. Ambas figuras quedan relegadas a un segundo plano en sus respectivos marcos de actuación, laboral y social en este caso. Por un lado, la traductora es considerada en muchas ocasiones como una máquina que simplemente se dedica a traducir y no siente ni padece; por otro lado, a ojos de una sociedad intrínsecamente patriarcal, se ve a la mujer como un instrumento a merced de dicha sociedad, alguien (o, en el peor de los casos, algo) sin voz ni voto.

A partir de estas relaciones analógicas que, consecuentemente y por fuerza, acaban derivando en la invisibilidad, opresión y menosprecio inequívoco de la figura femenina, se construye mi trabajo. Así, la relación entre la traductología y los estudios de género es más estrecha de lo que se podría pensar en un primer momento y me gustaría profundizar en los puntos de confluencia entre ambas disciplinas y en cómo la traductora puede convertirse en un motor de cambio social a través de su intervención en el texto origen.

Este trabajo ha de entenderse, pues, como una oportunidad para revisar y profundizar las cuestiones y los puntos más prácticos e importantes que a mi parecer se desprenden de la convergencia de la traducción y el feminismo.

\section{Objetivos}

El objetivo último y principal de este trabajo es una revisión de los conceptos que me parecen más importantes acerca de la traducción feminista, a través de lo que pretendo demostrar que el activismo feminista en el ámbito de la traducción y la interpretación es una práctica plausible que puede introducirse en la traducción de cualquier texto o la interpretación de cualquier discurso 
independientemente del contexto social, político y cultural, el idioma o la meta que persiga (siempre desde un enfoque interseccional que acomode a todos los grupos sociales que se representan). Además, deseo concienciar sobre la relación de las prácticas de traducción feminista con las estructuras de poder vigentes y su utilidad para acabar con estas y renovarlas.

De esta forma, analizaré detalladamente las relaciones entre feminismo y traducción, género y lenguaje y el importante papel del activismo, en este caso feminista, en la práctica traductora para romper con la percepción de la realidad social sexista derivada del empleo del lenguaje.

\section{Material y método}

Para realizar este trabajo necesité, en primer lugar, buscar las fuentes de documentación más adecuadas y relacionadas con los puntos que quería tratar, me documenté sobre autoras, teorías, estrategias y corrientes relacionadas con la traducción feminista, así como con el lenguaje, el género y el feminismo.

En segundo lugar, procedí a la lectura de dichas fuentes para poder conocer y contrastar diferentes perspectivas acerca de los temas relacionados con la traducción e interpretación, el lenguaje, el género y el feminismo. A medida que avanzaba con la lectura descubrí nuevos temas que me resultaban enriquecedores y descarté otros por ser, para mí, de orden secundario y por cuestiones de limitación de espacio. Así, me he basado en mi bibliografía y en mi concepción e ideas previas y experiencias acerca del tema de mi trabajo para poder delimitar los apartados definitivos de mi análisis teórico, teniendo en cuenta los temas que estaba interesada en tratar y prescindiendo de aquellos que no me parecían tan relevantes como para incluirlos en mi trabajo.

\section{Resultados}

\subsection{Género, lenguaje y conciencia}

Los textos se producen en un contexto ideológico y cultural concreto del que la traductora debe ser consciente en todo momento, pues la traducción es una práctica a la que afectan inevitablemente los factores políticos, sociales e ideológicos. Así, el contexto en el que se lleve a cabo la traducción es de gran relevancia, pues de él se desprenderán algunos aspectos (como los estereotipos sociales, las diferencias culturales o la idiosincrasia lingüística) dignos de tener en cuenta a la hora de traducir de forma congruente. Ser consciente de dicho contexto no conduce de manera 
irrevocable a cambiar el contenido, sino a tener conciencia por fin

del lenguaje con el que este se expresa y así poder analizarlo.

EI lenguaje estándar convencional es fundamentalmente patriarcal, ha sido creado por y para los hombres; von Flotow (1997) asevera que algunas escritoras de los setenta como Mary Daly o France Théoret opinaban lo siguiente: "Women live in exile in patriarchal language». Esta aserción puede parecer una exageración, pero el lenguaje, como bien apuntó Barthes (1953, citado por Monzó $2017,110)$ nunca es inocente, sino que es un arma poderosa que ha servido y continúa sirviendo como pilar fundamental para la construcción y el desarrollo de las estructuras de poder social y político que excluyen a las mujeres. Esta preeminencia del lenguaje patriarcal se consigue de formas más o menos subrepticias, entre las que destaca, por su permeabilidad y naturalización, el uso del masculino como genérico, que Goddard y Patterson $(2005,89)$ caracterizan del modo siguiente: «El uso de los términos masculinos en contextos supuestamente genéricos funciona para relegar a las mujeres del lenguaje, haciendo que sean "cognitivamente invisibles", es decir, que las excluye del pensamiento».

Así, a pesar de que el masculino genérico se intente vender como «neutral» y llegue avalado por instituciones patriarcales centenarias, nada más lejos de la realidad: se decanta activamente por un orden preestablecido de la sociedad patriarcal y entorpece la igualdad plena entre grupos sociales. Atendiendo al enfoque radical que he mencionado anteriormente, el hecho de emplear el masculino como genérico tiene como consecuencia directa la exclusión y no identificación de las mujeres dentro de la sociedad.

En realidad, como el resto de tácticas lingüísticas del patriarcado, el uso del masculino como genérico sería incluso anecdótico si no fuera porque el lenguaje construye y refleja una dimensión sociopolítica significativa, es decir, en una sociedad en la que no es extraño invisibilizar a las mujeres, sobre todo con miras a impedirles su acceso a espacios de poder varios, ocultarlas con el lenguaje puede entenderse como una argucia más para dificultar que eso ocurra siquiera como mera posibilidad.

Es importante, en este punto, mencionar la relación entre lenguaje y cognición, pues el lenguaje influye en el modo en el que organizamos nuestro sistema cognitivo, es decir, influye en la forma en que el cerebro organiza el pensamiento $y$ el conocimiento. $Y$ ejerce dicha influencia a través de un proceso de categorización, ya que la base del sistema cognitivo son las categorías.

En el caso del lenguaje patriarcal, se produce una categorización por género (masculino frente a femenino), a través de la que no solo se simplifican y homogeneizan grupos que son verdaderamente diversos, sino que también se incluye una categoría (femenina) dentro de otra (masculina) y se da mayor importancia a aquella que 
la sociedad patriarcal considera superior. Así, estas categorías realmente se crean en función de lo que la sociedad cree que es importante sobre las personas y, como indican Goddard y Patterson $(2005,75)$ :

hay pruebas de que si una categoría no es significativa para la sociedad no se emplea para describir o diferenciar a las personas, lo que también implica que cualquier categoría se podría volver importante en función de las convicciones que una sociedad tenga.

Por consiguiente, una traducción consciente en lo que a lenguaje y género respecta es esencial en el proceso traductor, pues puede ser capaz de revelar que el lenguaje no es fijo e inalterable y que las convicciones sociales igualmente pueden cambiar, $y$, desde esta conciencia lingüística de género, se puede iniciar y perfeccionar un importante proceso de deconstrucción del lenguaje y de la sociedad al mismo tiempo, y "la deconstrucción fuerza al máximo los límites del lenguaje. Se resiste a toda categorización y niega que en la traducción haya un significado único y estable que transmitir» (Vidal 1995, 91).

Las categorías, consecuentemente, son excluyentes. Aun así, la categoría masculina pretende abarcar en numerosas ocasiones tanto lo femenino como lo masculino; mientras que la femenina solo representa lo femenino. Las mujeres han de sentirse identificadas de forma indiscutible con la categoría masculina, mientras que los hombres nunca se sentirán de esta forma si se emplease una categoría femenina, que heriría gravemente su masculinidad. Este hecho desemboca innegablemente en una estructura de poder patriarcal: la idea de que no es legítimo ni razonable por parte de un hombre sentirse identificado con un grupo de mujeres, pero sí al contrario.

A pesar de que el uso de la categoría masculina pretende ser genérico y abarcar lo masculino y lo femenino, este uso del lenguaje conduce a implicaciones significativas desde un punto de vista cognitivo sobre todo porque se necesita un procesamiento 0 esfuerzo cognitivo adicional para percibir y entender que estamos ante un uso que pretende referirse a ambos géneros. Como afirman Goddard y Patterson $(2005,88)$ :

Este procesamiento secundario del significado genérico puede parecer bastante trivial si tenemos en cuenta el poco tiempo que tardamos en percibir un significado genérico frente a un significado exclusivamente masculino. Sin embargo, desde una perspectiva cognitiva y social, el impacto de esta primera lectura masculina tiene implicaciones muy importantes porque significa que pensamos en masculino a no ser que el contexto o algún marcador lingüístico nos indiquen lo contrario. 
Esta última frase ciertamente invita a la reflexión y a la toma de conciencia. Asimismo es una evidencia más del peso que tiene el lenguaje en la construcción cognitiva, social y moral del individuo.

Además, existen otras hipótesis que refuerzan esta noción de la relación entre lenguaje y cognición: la de Sapir-Whorf, dos estudiosos que llegaron a la conclusión de que aprehendemos la realidad a través del lenguaje. En otras palabras, ambos defienden que nuestras ideas sobre el entorno son el resultado del lenguaje que empleamos y que el lenguaje influye e incluso determina cómo percibimos la realidad y cómo pensamos (Gibbon 1999).

Así, la traducción feminista, que, de forma más o menos utópica, tiene en cuenta todos los aspectos anteriores en su puesta en práctica, ha de comprenderse como una forma más de emancipación de un sistema que toma al hombre como modelo al que equipararse y piensa que hombre siempre es sinónimo neutro de persona. De hecho, la traducción puede participar como engranaje dentro de la maquinaria del feminismo a fin de contribuir a la liberación de las cadenas del patriarcado. Ahora bien, para ello se ha de tener conciencia de género y esto, a la par que costoso, puede ser un desafío en toda regla debido a que toda la estructura social, política y cultural se yergue sobre unos cimientos firmes y bien asentados desde hace siglos. Por ello puede resultar complejo superar esta alienación lingüística, embarcarse en el proceso de deconstrucción y comprender el poder último que el lenguaje ejerce sobre toda la sociedad.

\subsection{Intervencionismo del traductor feminista}

Las traductoras, como el resto de individuos de la sociedad, poseen una ideología propia. Esto no significa que todas la reflejen de manera explícita en sus traducciones, pero cuando existe un posicionamiento firme como podría ocurrir con el feminismo, la conciencia feminista en muchas ocasiones se evidencia a través de la actividad traductora dando lugar a traductoras y traducciones indiscutiblemente politizadas de una manera $u$ otra.

El intervencionismo deliberado puede resultar controvertido, ya que se espera que las traductoras eviten incluir sus posicionamientos políticos en sus textos y sigan actuando como máquinas que trasladan información de un idioma a otro. Cuando las traductoras feministas actúan de acuerdo con su ideología se produce un desconcierto que pocas prácticas traductoras provocan y es que, como apunta Luise von Flotow $(1997,25)$ :

When feminist translators intervene in a text for political reasons, they draw attention to their action. In so doing, they demonstrate how easily misogynist aspects of patriarchal language can be dismantled once they have been detected. 
O bien como también opina Sherry Simon $(1996,12)$ sobre esta

misma cuestión: «Because it is an activity which has long been theorized in terms of a hierarchy of gendered positions, the rethinking of translation will necessarily upset traditional vocabularies of domination".

Así, la traducción de un texto se convierte en una práctica política relevante y en la materialización del encuentro entre la ideología feminista y el proceso traductor, cuyo objetivo es reescribir haciendo visible el femenino y lograr que el lenguaje represente también a las mujeres. Sin embargo, a menudo la traducción feminista se concibe como un acto de traición premeditada al texto origen que solo pretende destruirlo. Esta confusión recurrente es fruto una vez más de la alienación y del desconocimiento del poder del lenguaje. Sin embargo, el propósito del intervencionismo traductor feminista radica en visibilizar la presencia de la mujer a través del empleo de las palabras de las que dispone una lengua. Como afirman Goddard y Patterson (2005, 105):

La idea de «interferir» en el lenguaje resulta interesante, porque asume que el lenguaje es un producto natural más que una creación humana. Es fácil sentir que los orígenes del lenguaje están muy lejos en el tiempo y que el proceso de crear significado ya está terminado por completo. No obstante, este proceso es constante, delante de nuestras narices.

Es decir, la humanidad tuvo el poder de crear el lenguaje y por consiguiente también tiene el poder de cambiarlo si es necesario, pero para ello hay que ser consciente de la necesidad imperiosa de cambio y, sobre todo, de actuación.

Ahora bien, es cierto que hay cuestiones en cuanto al intervencionismo feminista para las que no existen respuestas universales concluyentes ni normas generales que se deban aplicar en cualquier caso, el intervencionismo depende enteramente de las decisiones de la traductora, pues como presenta Hurtado Albir (2001) en su libro Traducción y traductología: introducción a la traductología, traducir es un proceso de toma de decisiones y elección. Parte de la conciencia traductora reside, a mi parecer, en saber cuándo y cómo se debe «manipular» deliberadamente un texto, aunque toda traducción implique cierto grado de «manipulación» del texto origen en mayor o menor medida.

Por ejemplo, que un texto no sea abiertamente misógino ni ataque directamente a las mujeres no quiere decir que las mujeres se vean representadas en su contenido. En otras palabras, si el contenido del texto no está adscrito a ninguna ideología explícita, puede deducirse que esta falta de carga ideológica se traduce en una adscripción a la ideología dominante y que, por lo tanto, una traducción de esa misma naturaleza también estará subordinada a la 
ideología dominante: la patriarcal. Las traductoras que no son conscientes de esta ideología dominante se convierten entonces en «ingenuos vehículos de transmisión y legitimación del discurso dominante» (Castro Vázquez 2009, 63).

Además, cuando se intervenga un texto se ha de tener en cuenta que la perspectiva de partida no es siempre la de un feminismo puramente occidental (como podría ocurrir al traducir obras de autoras indias o africanas) y que dentro del propio movimiento feminista será necesario "observar las diferencias entre las diversas experiencias femeninas atendiendo a las distinciones de las mujeres en cuestión y enfatizando la necesidad de contextualizar" (Salvador 2006), pues siempre habrá diferentes posturas, enfoques y estadios que valorar antes de abordar la traducción.

Así, las decisiones personales de la traductora, aquellas que están motivadas por su ideología y su moral feminista, tienen un gran peso en el proceso traductor en general y en las soluciones concretas en particular a pesar de no ser ninguna de ellas inocente ni inocua (Brufau Alvira 2011, 193). Si algo queda claro es que el intervencionismo feminista como acción política y la incorporación de la ética traductora desde una perspectiva de género son prácticas viables en la traducción de cualquier texto y que, además, citando a Olga Castro $(2009,63)$, «la objetividad y neutralidad en traducción son falacias interesadas».

\subsection{La traductora infiel}

Uno de los escollos con los que más a menudo se topa la traductora feminista es, sin lugar a dudas, el cuestionamiento externo. La traducción feminista se enfrenta a las prácticas traductoras clásicas $y$, por consiguiente, es objeto de estigmatización. En muchas ocasiones, aplicar una perspectiva de género e intentar evitar el sexismo y androcentrismo lingüístico «no solo comporta dificultades lingüísticas, sino otras de índole social que se mezclan en el maremágnum político común» (Brufau Alvira 2011, 193).

No es disparatado que la traductora, abogando por ser fiel a su conciencia, opte por una traducción feminista. Si se decanta por la reescritura en femenino o incluso por estrategias menos agresivas de inclusión lingüística, esto la posicionará políticamente, de manera voluntaria o involuntaria. A ojos de una sociedad y unas instituciones patriarcales, este comportamiento supone una infidelidad no solo al texto sino también a los constructos sociales.

Como consecuencia, la actividad traductora feminista se enfrenta continuamente a una serie de dilemas (muchas veces dicotómicos) a varios niveles: fidelidad-infidelidad, naturalidadartificialidad, equivalencia-reformulación, legitimidad-engaño, que parecen no tener fin y ante los que las decisiones personales basadas 
en la ideología de la traductora se presentan como el único desenlace lógico. Si se adopta un enfoque traductor feminista radical, la solución resulta más que obvia: hay que subvertir y socavar el texto de manera sistemática si este ataca a nuestros ideales, no se necesitan motivos categóricos para actuar, porque tal y como describe von Flotow a de Lotbinière-Hardwood: "She offers no excuses or justifications for feminist intervention in texts, but an abudance of compelling reasons» (de Lotbinière-Hardwood, citada en von Flotow 1997, 27).

Las críticas de los detractores sobre esta reescritura o reformulación en femenino ponen en tela de juicio su validez y dificultan la expansión de su práctica. Incluso cuando se emplean estrategias menos agresivas que la reformulación total como técnicas de inclusión o generalización, se encuentran opositores que denuncian la transgresión a la economía lingüística, tan interiorizada y cómoda para muchas instituciones patriarcales; o la artificialidad y falta de idiomatismo del texto meta, que en realidad es producto de la falta de costumbre por incluir prácticas traductoras distintas a las tradicionales.

A raíz de estas acusaciones de infidelidad o incluso traición al texto original, surge una polémica dicotomía fidelidad-infidelidad: si la traductora es totalmente fiel al texto origen, corre el riesgo de ser infiel a su ideología y viceversa. Cuando la traductora se decanta por serle infiel al texto y mantenerse fiel a su moral feminista ocurre lo que Martín Ruano (citada en Calefato y Godayol 2008, 51) define como "fidelidad subversiva aunque "fidelidad" a fin de cuentas".

Por supuesto, una de las tareas de la traductora es que el texto traducido sea natural, idiomático y una reproducción lo más exacta posible del original, así que ¿no supone en este punto la traducción feminista un obstáculo evidente? El sobreempleo de genéricos y epicenos puede resultar poco familiar, el uso de barras y dobletes puede llegar a hastiar a quien reciba el texto meta y la reescritura o reformulación en femenino, con total probabilidad, causará un desconcierto enorme en el público. Estos hechos llevarán a la traductora a enfrentarse de forma continuada a situaciones delicadas en su trabajo y a rivalizar con un mundo en el que se premia y legitima una aparente normalidad asentada en unos rancios valores patriarcales.

Ahora bien, la traductora feminista, subversiva e infiel, lejos de tirar la toalla siempre puede buscar fuerza y consuelo en las palabras de Susanne de Lotbinière-Hardwood (citada en von Flotow 1997, 79; 1991, 29): "Making the feminine visible in language means making women seen and heard in the real world, which is what feminism is all about». 


\subsection{Aplicación de la traducción feminista en la interpretación}

A pesar de que pueda resultar obvio, la forma de trasladar un mensaje de forma no sexista y la reformulación en femenino pueden ser más problemáticas en el campo de la interpretación. Esto ocurre principalmente en interpretación simultánea, porque en ella no se dispone de un periodo de tiempo para la reflexión ni para el análisis minucioso de las palabras.

Incluso a partir de mi corta experiencia en el área de la interpretación, he detectado que existen dos problemas principales y recurrentes a los que hacer frente y los he plasmado en una tabla que se encuentra más adelante (tabla 1). En primer lugar, surge una disyuntiva cuando en una lengua con género gramatical explícito (como el español) se presenta un (falso) masculino genérico ante el que la traductora debe decidir si hacer un desdoble masculinofemenino o mantener el masculino (1). En segundo lugar, esto mismo puede suceder por supuesto en el caso contrario, si se trabaja desde una lengua en la que no suele haber marca de género (como el inglés) (2).

Para ilustrar los casos anteriores me he basado en algunos de los discursos (FEND Lectures y On Being Wrong) que hemos utilizado en la asignatura de Interpretación Simultánea (2) y también en un ejemplo (1) que proporciona Olga Castro (2009), aunque he de apuntar que su ejemplo no tiene la intención de ilustrar casos que se dan en interpretación concretamente, sino en una traducción en general.

Tabla 1.

\begin{tabular}{|c|c|c|c|c|}
\hline & ES & EN & FR & $\mathrm{DE}$ \\
\hline 1 & Mis tíos & $\begin{array}{l}\text { My uncle and } \\
\text { aunt } \\
\text { My uncles } \\
\text { My aunt and } \\
\text { uncles } \\
\text { My aunts and } \\
\text { uncle }\end{array}$ & $\begin{array}{l}\text { Mon oncle et ma } \\
\text { tante } \\
\text { Mes oncles } \\
\text { Ma tante et mes } \\
\text { oncles } \\
\text { Mes tantes et } \\
\text { oncles }\end{array}$ & $\begin{array}{l}\text { Mein Onkel und } \\
\text { meine Tante } \\
\text { Meine Onkel } \\
\text { Meine Tante und } \\
\text { meine Onkel } \\
\text { Meine Tanten } \\
\text { und meine Onkel }\end{array}$ \\
\hline 2 & $\begin{array}{l}\text { Enfermera } \\
\text { Enfermero }\end{array}$ & Nurse & $\begin{array}{l}\text { Infirmière } \\
\text { Infirmier }\end{array}$ & $\begin{array}{l}\text { Krankenschweste } \\
\text { r Krankenpfleger }\end{array}$ \\
\hline & $\begin{array}{l}\text { Amiga } \\
\text { Amigo }\end{array}$ & Friend & $\begin{array}{l}\text { Amie } \\
\text { Ami }\end{array}$ & $\begin{array}{l}\text { Freundin } \\
\text { Freund }\end{array}$ \\
\hline
\end{tabular}

En estos casos, existe un riesgo evidente de incurrir en una traición al TO tanto si se opta por la traducción feminista como si no, 
pues la situación es de desconocimiento total del género del sustantivo que la oradora ha mencionado.

Otra de las trabas con respecto a la práctica de traducción feminista y no sexista en la interpretación es el tiempo. En la interpretación simultánea el tiempo puede ser nuestro mayor aliado o nuestro peor enemigo: mejor dicho, el desfase temporal con respecto al TO. El hecho de querer deshacernos del lenguaje sexista en nuestra reformulación del discurso puede conducirnos a aumentar dicho desfase y provocar que, por ejemplo, ya no podamos reengancharnos al ritmo del discurso original, lo que puede ser muy peligroso. No es lo mismo decir: «doy la bienvenida a todas las enfermeras de Europa a esta conferencia» que "doy la bienvenida a todas las enfermeras y enfermeros de Europa a esta conferencia» o que «doy la bienvenida al personal de enfermería de Europa a esta conferencia».

Cuando se dan casos como los anteriores, la traductora se ve de nuevo rodeada de dilemas en lo que a la manera de reformular respecta. Sin embargo, el proceso de interpretación no deja tiempo para que se reflexione acerca de qué decisión tomar con tranquilidad, por lo que la solución para una traductora con un posicionamiento ético feminista firme (radical) sería, por supuesto, la reformulación en femenino y el empleo de lenguaje inclusivo en todo momento, a riesgo de que esta práctica tan poco convencional choque a la audiencia.

\subsection{Traducir en femenino: estrategias}

Como vengo manifestando a lo largo de todo mi escrito, la traductora feminista tiene el poder de «manipular» el texto si lo considera oportuno e incluir en él su ideología para liberarlo de su carga patriarcal. Para conseguir este objetivo, puede recurrir al empleo de diferentes estrategias textuales y discursivas de traducción feminista. Me basaré principalmente en los ejemplos y las estrategias propuestas por Castro Vázquez (2010) en su artículo "Género y traducción: elementos discursivos para una reescritura feminista", puesto que me han parecido tan prometedoras como aplicables.

En primer lugar, una de las estrategias más recurrentes para evitar el lenguaje no sexista es la generalización o neutralización. Consiste en sustituir el término sexista por uno neutro o un epiceno que designe de igual manera a individuos de ambos géneros independientemente del género gramatical del sustantivo (estudiante, bebé). Así se evita indicar el género de forma explícita. Sin embargo, se ha de tener en cuenta la tendencia a entender los sustantivos neutros como masculinos como consecuencia del «MaleAs-Norm Principle» o «MAN Principle», por el cual se suele optar por el masculino si se desconoce el género del sujeto. 
Otra técnica es la feminización o especificación. Esta práctica supone visibilizar las marcas de género gramatical para también visibilizar a las mujeres en el lenguaje; es decir, aparece el género correspondiente al referente que se ha mencionado (masculino si es hombre, femenino si es mujer, ambos géneros si son mujer y hombre o si hay desconocimiento del género del referente). Algunos de los recursos mencionados por Castro Vázquez son paréntesis, barras, guiones, mayúsculas, arrobas y dobletes. Me gustaría hacer una añadidura, una innovación más o menos reciente: el empleo de la $\boldsymbol{x}$ para sustituir a las letras que funcionan como marca de género y que se emplea principalmente en las redes sociales (chicxs; queridxs alumnxs; amigxs). Realmente la considero una renovación y mejora de la arroba, pues es más discreta dentro del conjunto textual (llama menos la atención porque la arroba es más grande y ni siquiera es una letra) y, además, en la arroba la $\boldsymbol{a}$ parece estar contenida o, cuando menos rodeada, por la $\boldsymbol{o}$, lo cual podría representar gráficamente la subyugación del mundo femenino por el masculino.

Las estrategias anteriores son las más conocidas y habituales para hacer uso de un lenguaje más inclusivo y no sexista, tanto en la práctica de traducción feminista como en otras prácticas traductoras. A continuación voy a presentar varias técnicas que también pueden resultar muy útiles en la práctica traductora feminista y que más bien se encuadran en un enfoque radical:

- La suplementación o compensación. Consiste en compensar las diferencias entre lenguas y culturas intentando conservar el significado y las connotaciones del original. Algunas reconocidas traductoras feministas como LotbinièreHardwood, que resaltó las marcas de género del francés al traducir al inglés, o Goddard, que traduce el libro Amantes como LoveHers para advertir que se trata de lesbian lovers, son claros ejemplos de la puesta en práctica de esta estrategia.

- La metatextualidad. Esta práctica se basa en incluir prefacios, notas de la traductora, prólogos y otros paratextos que expliquen y justifiquen el intervencionismo que se ha llevado a cabo en el texto. A través de esta estrategia, la traductora también consigue dar visibilidad a su actividad. Uno de los ejemplos más representativos de esta técnica es el prólogo de Susanne de LotbinièreHardwood en la que explica el uso de her en other, pues tradujo Lettres d'une autre (1987), de Lise Gauvin, como Letters from An Other. En dicho prólogo (de LotbinièreHarwood, en Gauvin, 1989, citado en von Flotow 1997, 29) dejaba clara su ideología feminista: 
Dear reader,

Just a few words to let you know that this translation is a rewriting in the femenine of what I originally read in French. I don't mean content. Lise Gauvin is a feminist, and so am I. But I am not her. She wrote in the generic masculine. My translation practice is a political activity aimed at making language speak for women. So my signature on a translation means this translation has used every possible feminist translation strategy to make the femenine visible in language.

- El secuestro. Es una estrategia por la que la traductora se apropia de un texto con lenguaje patriarcal y lo reescribe utilizando neologismos, introduciendo cambios, sustituyendo el masculino genérico por el femenino genérico, eliminando elementos sexistas, resaltando algunos elementos... Un ejemplo de esta modalidad es el mismo que el de la anterior, pues la traducción de Lotbinière-Hardwood de Lettres d'une autre es una reescritura en femenino usando el secuestro en toda regla; o también la traducción de textos de Cabrera Infante que llevó a cabo Suzanne Jill Levine (citado en Castro 2009)

- La coautoría o pacto especular, término acuñado por MarieFrance Dépêche (2002, citada en Castro Vázquez 2010, 296). Esta cuarta estrategia traductora feminista consiste en la colaboración entre quien escribe y quien traduce, de manera que se consiga la coautoría de la obra traducida. Esta técnica se puso en práctica en la traducción de la obra de Nicole Brossard (1998) Elle serait la première phrase de mon prochain roman / She would be the first sentence of my next novel, que Lotbinière-Harwood tradujo al inglés.

Junto con la feminización y la generalización, estas cuatro estrategias de suplementación, metatextualidad, secuestro y coautoría constituyen la puesta en práctica de la ideología y los principios éticos y morales de la traductora feminista, así como la materialización de un empeño incesante por hacer a la mujer visible a través del lenguaje $y$, por ende, visible en la sociedad. Desde este punto de vista en el que la traductora desempeña un papel activo en el proceso de traducción y opta por la práctica de algunas de las técnicas y estrategias anteriores, Goddard (citada en Bertacco, 2003: 237) afirma lo siguiente: "translation detaches itself more and more from the ideal of quest for equivalence and, instead, presents transformation as performance as its model».

También es importante mencionar que en España, instituciones, asociaciones y otros organismos como la Secretaría General de Políticas de Igualdad, el Instituto de la Mujer y la Federación de 
Mujeres Progresistas han elaborado manuales de escritura no sexista

(Brufau Alvira, 2011: 191). Existe un recurso informático, una base de datos más concretamente, elaborada por el grupo NOMBRA (Comisión Asesora sobre Lenguaje del Instituto de la Mujer) que facilita opciones alternativas de escritura para evitar el lenguaje sexista y se puede descargar de manera gratuita. Esta herramienta consta de tres pestañas: palabras ante las que conviene extremar el cuidado (imagen 1), una lista general de expresiones de uso problemático (imagen 2) y expresiones frecuentes (imagen 3). En la primera de ellas, además de opciones para sustituir el término en masculino por otros inclusivos, se muestran el contexto original en el que se encuentran la palabra o palabras y el contexto alternativo con la nueva opción. En la tercera, junto con los contextos, se muestra un apartado de ejemplos en corpus.

Iniciativas como la de NOMBRA impulsan el empleo de lenguaje inclusivo y constituyen herramientas útiles e innovadoras en pro de la eliminación gradual del lenguaje sexista y androcentrista.

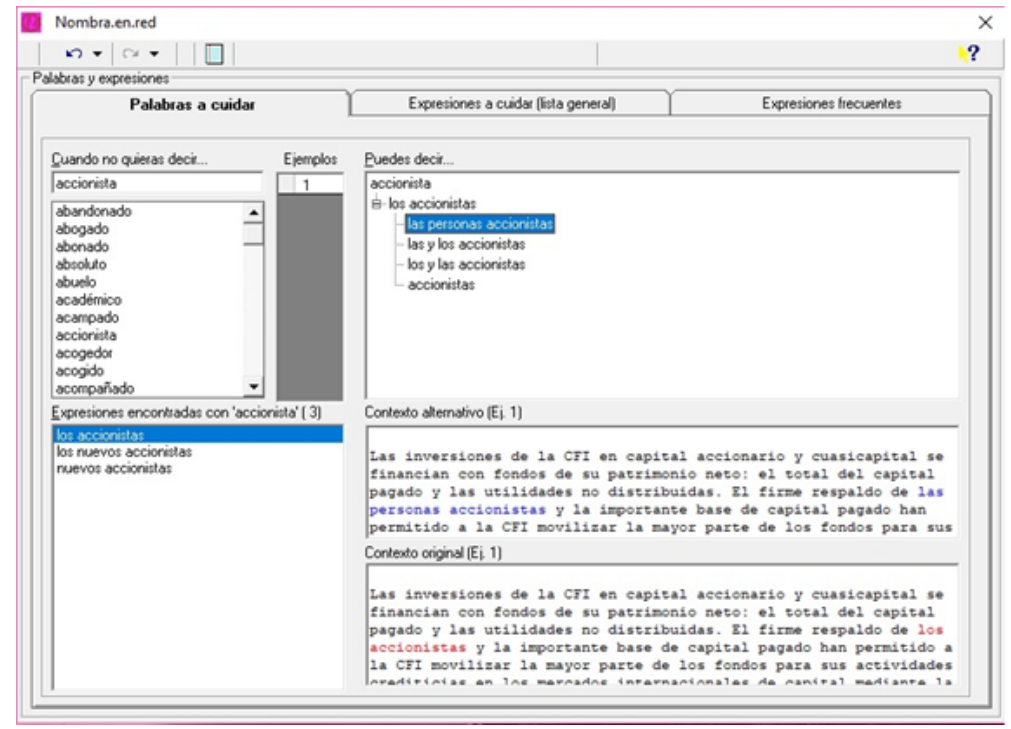

Imagen 1 


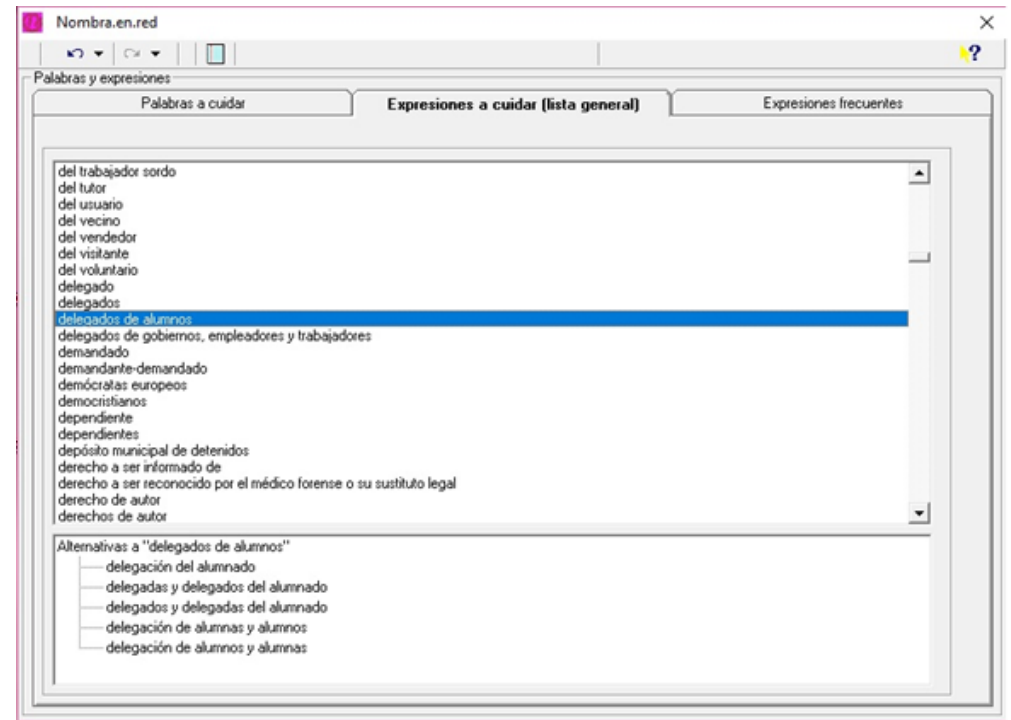

Imagen 2

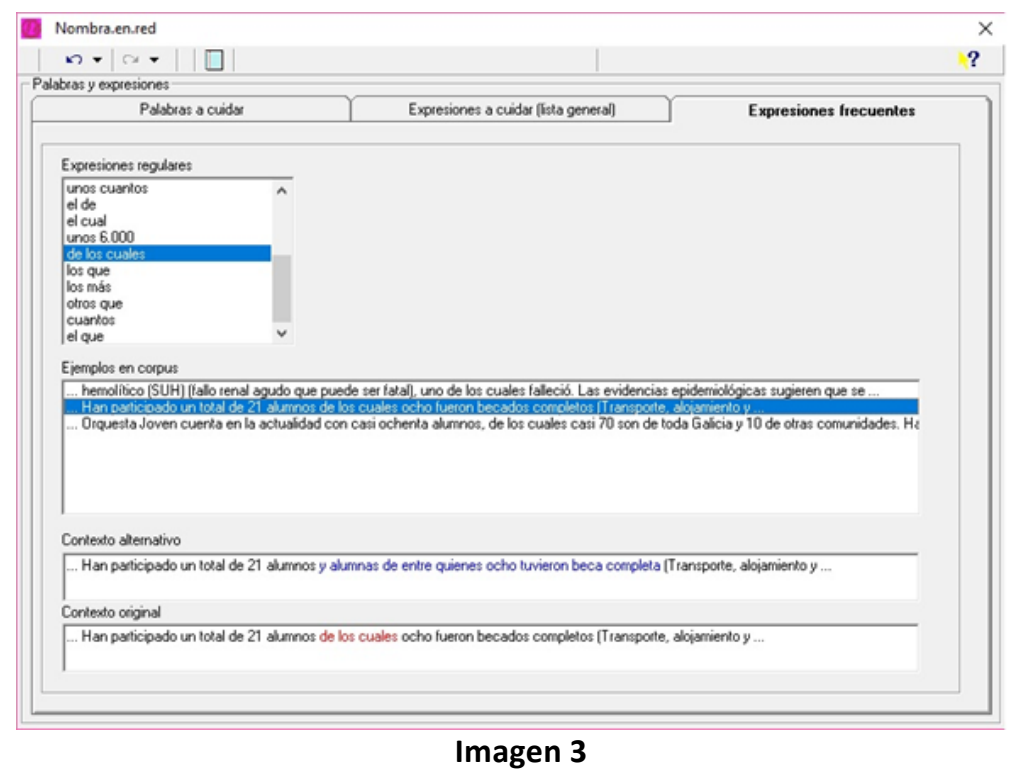

\section{Discusión y conclusiones}

Concluyo este trabajo con la certeza de que ha sido un incipiente proceso de introspección que me ha servido como punto de partida para comenzar a adentrarme en la traducción feminista, un campo de estudio que me fascina y sobre el que llevaba tiempo queriendo saber más. A medida que me he sumergido en las páginas de escritoras, en general todas ellas feministas, no solo he aprendido acerca de feminismo y traducción, sino que me he dado cuenta de que ambos campos de estudio están estrechamente relacionados con otras cuestiones que no habría podido imaginar, como por ejemplo la cognición.

Soy consciente de que los objetivos no eran extremadamente ambiciosos y de que las cuestiones que he revisado son las que a mí 
más me llamaban la atención. Así que, llegada a este punto, puedo aseverar que la hipótesis queda confirmada: existe una relación patente entre feminismo y traducción, en otras palabras, entre los estudios de género y los ET, que se materializa en la traducción feminista. Además, la puesta en práctica de la traducción feminista, es decir, introducir el intervencionismo y la conciencia feminista en las prácticas de traducción es posible en mayor o menor medida dentro del marco sociopolítico actual a pesar de su falta de normalización (que espero vaya disminuyendo de forma progresiva). Queda también comprobado que se trata de una actividad política y social por los objetivos que persigue, entre los que están principalmente dar visibilidad y voz a la mujer dentro de una sociedad patriarcal que quiere acallarla y tratar de poner fin a la perpetuación de las estructuras de poder impuestas por esta sociedad.

Las conclusiones teóricas a partir del trabajo conducen a su vez a reflexiones de índole más bien social, política y moral, pues me han permitido ratificar la importancia de tener una postura ideológica firme. Leer experiencias reales de traductoras y ejemplos concretos de traducciones feministas ha sido clave para una mejor comprensión de lo que realmente significa subvertir un texto y hacerlo tuyo como traductora. Esto ha ocurrido gracias a la lectura de las obras de traductoras feministas, mujeres deconstruidas, subversivas y con una ideología fundada, como LotbinièreHardwood, Goddard, Simon, Castro Vázquez, Brufau Alvira, etc., que se han encargado de articular y desplegar una amplia maquinaria de teoría y praxis en lo que a traducción feminista respecta, de modo que han permitido que esta continúe creciendo cada día a través del interés, el estudio y la lucha de las nuevas generaciones de traductoras feministas.

La elaboración de este trabajo ha sido, en definitiva, un proceso de (de)construcción constante que, además de ampliar mis conocimientos en estas áreas de estudio, me ha permitido crecer como estudiante, como traductora y como persona.

\section{Bibliografia}

de Beauvoir, Simone. 2017. Le deuxième sexe. París: Gallimard.

Bertacco, Simona. 2003. "The Canadian Feminists' Translation Project: Between Feminism and Postcolonialism». Linguistica Antverpiensia, New Series - Themes in Translation Studies 2: 233-245.

Brufau Alvira, Nuria. 2011. "Traducción y género: el estado de la cuestión en España». MonTI. Monografías de Traducción e Interpretación 3: 181-207. 
Calefato, Patrizia, y Pilar Godayol. 2008. Traducción, género, poscolonialismo. Buenos Aires: La Crujía.

Calzada Pérez, María. 2007. El espejo traductológico: teorías y didácticas para la formación del traductor. Barcelona: Octaedro.

Castro Vázquez, Olga. 2009. "(Re)examinando horizontes en los estudios feministas de traducción: ¿hacia una tercera ola?» MonTI. Monografías de Traducción e Interpretación 1: 59-86.

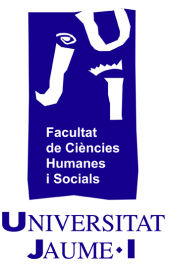

—. 2010. "Género y traducción: elementos discursivos para una reescritura feminista». Lectora: Revista de Dones i Textualitat 14: 285-302.

von Flotow, Luise. 1991. "Feminist Translation: Contexts, Practices and Theories». TTR: Traduction, Terminologie, Rédaction 4 (2): 69-84.

-. 1997. Translation and gender: translating in the "era of feminism». Manchester, Ottawa: St. Jerome Publishing; University of Ottawa Press.

Gibbon, Margaret. 1999. Feminist Perspectives on Language. Feminist Perspectives Series. Londres: Addison Wesley Longman.

Goddard, Angela, y Meân Patterson. 2005. Lenguaje y género. Cuenca: Universidad de Castilla-La Mancha.

Hurtado Albir, Amparo. 2001. Traducción y traductología: introducción a la traductología. Madrid: Cátedra.

Monzó Nebot, Esther. 2017. «The out-grouping society: phrasemes othering underprivileged groups in the International Bill of Human Rights (English-French-Spanish)». Phraseology in legal and institutional settings: a corpus-based interdisciplinary perspective, editado por Stanislaw Goźdź-Roszkowski y Gianluca Pontrandolfo, 131-159. Londres: Routledge

Munday, Jeremy. 2001. Introducing translation studies: theories and applications. Londres; Nueva York: Routledge.

Saint-Martin, Lori. 1992. "Susanne de Lotbinière-Harwood: Re-belle et infidèle: la traduction comme pratique de réécriture au féminin. The Body Bilingual: Translation as a Rewriting in the Feminine». Recherches féministes 5 (1): 204-207.

https://doi.org/10.7202/057690ar.

Salvador, Dora Sales. 2006. "Traducción, género y poscolonialismo: compromiso traductológico como mediación y affidamento femenino». Quaderns: Revista de traducció 13: 21-30.

Sau, Victoria. 1990. Diccionario ideológico feminista. 2a. ed. ampliada y rev. Barcelona: Icaria. 
Schulz, Kathryn. 2011. «On being wrong». Vídeo de TED Talks. Acceso https://www.ted.com/talks/kathryn_schulz_on_being_wrong.

Simon, Sherry. 1996. Gender in translation: cultural identity and the politics of transmission. Londres: Routledge.

Vidal, M. Carmen África. 1995. Traducción, manipulación, desconstrucción. Salamanca: Ediciones Colegio de España. 